\title{
MICROWAVE-ASSISTED LIQUID PHASE MICROEXTRACTION FOLLOWED WITH FLAME ATOMIC ABSORPTION SPECTROMETRY FOR TRACE DETERMINATION OF ZINC IN FOOD SAMPLES
}

\author{
KOUROSH MOTEVALLII, ZAHRA YAGHOUBI
}

Department of Applied Chemistry, Faculty of Science, Islamic Azad University, South Tehran Branch, Tehran, Iran

\begin{abstract}
In this work, microwave-assisted liquid phase microextraction (MA-LPME) was followed by flame atomic absorption spectrometry for determination of zinc in food samples. Zinc was complexed with a chelating agent to form hydrophobic species.1-hexyl-3-methylimidazolium hexafluorophosphate ([Hmim][PF $]$ ) ionic liquid (IL) was used as environmentally-friendly extraction solvent. In order to disperse the extraction phase into the sample solution and improve the extraction efficiency, microwave irradiation was used as a disperser agent. The heating effect of microwave irradiation makes the ionic liquid dissolved and dispersed through the sample, which significantly improves the speed and efficiency of extraction. After extraction process, sample solution was centrifuged and the settled phase was diluted and introduced to flame atomic absorption spectrometry by conventional aspiration. Various parameters including amount of ionic liquid, microwave power, irradiation time, $\mathrm{pH}$, amount of chelating agent and salt amount were studied and optimized. At optimized condition, a limit of detection (LOD) of $1.5 \mathrm{ng}$ $\mathrm{mL}^{-1}$, a linear range of 5-32 ng mL${ }^{-1}$ and a RSD of 4.3\% were obtained. Finally, the developed protocol was utilized for determination of zinc in food samples.
\end{abstract}

Keywords: Microwave-assisted liquid phase microextraction. Zinc. Atomic absorption spectrometry. Food sample.

\section{INTRODUCTION}

Zinc is a heavy metal and has great nutritional importance. In order to prevent growth retardation, altered immune response, premature birth, weight loss, and anorexia, recommended level of this element $\left(15 \mathrm{mg} \mathrm{L}^{1}\right)$ must be used per day. ${ }^{1}$ But in higher level, this heavy metal can be toxic and cause some damages including disturbances in energy metabolism or increasing in oxidative stress..$^{2-4}$ As a result, trace determination of zinc in real samples is important task of chemist.

In literature, several methods including flame atomic absorption spectrometry (FAAS), ${ }^{5}$, electrothermal atomic absorption spectrometry (ETAAS), ${ }^{6}$ inductively coupled plasma optical emission spectrometry (ICPOES), electrochemical methods ${ }^{8,9}$ and fluorimetry ${ }^{10}$ have been developed for determination of zinc in real samples. But in many cases, the amount of zinc is below the quantification limit of analytical instrument and complex matrix of the sample may interfere with analysis of zinc. As a result, development and application of a practical preconcentration method before analysis is important. ${ }^{11-13}$

In recent years, one of the most popular sample pretreatment methods is liquid phase microextraction (LPME), which the amount of toxic extraction solvents significantly decreases and LPME has more compatibility with green chemistry rules.

Ionic liquids (ILs) have received much attention as the green solvents to replace traditional toxic organic extraction solvents in sample enrichment methods. These ionic compounds have special physicochemical properties including low vapor pressure, adjustable solubility, variety density and etc. ${ }^{14-16}$ Regarding the practical properties of ILs, these materials have been widely applied in LPME as the extracting solvent. ${ }^{17-23}$

One of the major problems of the previously reported microextraction methods is the application of a disperser solvent. In the presented method, a practical LPME based on the application of microwave irradiation is developed for preconcentration and analysis of zinc in food samples. In this work, 1-hexyl3 -methylimidazolium hexafluorophosphate ([Hmim][PF ]) ionic liquid (IL) is used as extraction solvent. Zinc was complexed with a chelating agent to form hydrophobic specie. In order to disperse the extraction phase into the sample solution and extract analyte of interest, microwave irradiation is utilized. There is no need for utilization of a disperser solvent. The heating effect of microwave irradiation makes the ionic liquid dissolved and dispersed through the sample, which significantly improves the speed and efficiency of extraction. Sample solution is centrifuged and the settled phase is diluted and introduced to flame atomic absorption spectrometry. Various parameters including amount of ionic liquid, microwave power, irradiation time and salt amount were studied and optimized. Finally, microwave-assisted liquid phase microextraction (MALPME) was followed by flame atomic absorption spectrometry for trace determination of zinc in food samples.

\section{EXPERIMENTAL}

\section{Apparatus}

Measurements were performed using a Shimadzu AA-6800 flame atomic absorption spectrometer (Kyoto, Japan) equipped with an air acetylene flame and a zinc hollow-cathode lamp (current of $5 \mathrm{~mA} /$ spectral bandpass of 0.9 $\mathrm{nm}$ ). For quantification of zinc the wavelength of the lamp was tuned at 213.7 $\mathrm{nm}$. The microextraction was performed using a house hold micro-wave oven (SANYO, China). The applied microwave provided a maximum output power of $500 \mathrm{~W}$.

\section{Reagents and materials}

Analytical grade of all chemical were used. 1-hexyl-3-methylimidazolium hexafluorophosphate $[\mathrm{Hmim}]\left[\mathrm{PF}_{6}\right]$ ionic liquid, oxime, acetone, hydrochloric acid, sodium hydroxide, acetonitrile, methanol and ethanol were prepared from Merck. A stock solution of zinc was obtained by dissolving desire amount of zinc nitrate in distilled water. Working solutinons of zinc were prepared by step dilution of stock solution. A $0.002 \mathrm{~mol} \mathrm{~L}^{-1}$ solution of oxime was prepared as the chelating agent.

\section{Microwave-assisted liquid phase microextraction (MA-LPME)}

In this microextraction method, $10 \mathrm{~mL}$ of aqueous sample, which contains zinc, oxime and $\mathrm{NaCl} 5 \%$, was placed in centrifuge tube. The $\mathrm{pH}$ of the sample was adjusted at 10 using sodium hydroxide solution $\left(0.01 \mathrm{~mol} \mathrm{~L}^{-1}\right)$. Then, 60 $\mathrm{mg}$ of $[\mathrm{Hmim}]\left[\mathrm{PF}_{6}\right]$ ionic liquid was added to the sample. Sample tube was placed in microwave oven and irradiated under power of $150 \mathrm{~W}$ for $75 \mathrm{~s}$. In this step, ionic liquid is completely dissolved and dispersed through the sample solution. Hydrophobic complex of zinc was extracted into the tiny drops of extracting phase (ionic liquid). After centrifugation at speed of $4000 \mathrm{rpm}$ and time of $4 \mathrm{~min}$, ionic liquid containing zinc-oxime was settled at the bottom of the test tube. The upper phase was removed with a syringe and the settled phase was diluted with ethanol. Afterwards, the pre-concentrated phase was introduced to flame atomic absorption spectrometry for quantification of zinc.

\section{Sample preparation for food samples}

$1 \mathrm{~g}$ of apple, potato or flour was kept in oven at $150^{\circ} \mathrm{C}$, in order to completely be dried. Afterwards, the samples were put in furnace at $500{ }^{\circ} \mathrm{C}$ to result dryashed residue. The resulting sample was cooled at room temperature and 15 $\mathrm{mL}$ concentrated nitric acid and $5 \mathrm{~mL} \mathrm{H}_{2} \mathrm{O}_{2} 30 \%$ were added, and was put in furnace for $4 \mathrm{~h}$ at temperature of $500{ }^{\circ} \mathrm{C} .{ }^{2}$ Afterwards, $5 \mathrm{~mL}$ concentrated $\mathrm{HCL}$ and $5 \mathrm{~mL} \mathrm{HCLO} \mathrm{H}_{4} 70 \%$ were added to residue and evaporated. The resulting sample was diluted to $100 \mathrm{~mL}$ and subsequent analysis was performed.

\section{RESULTS AND DISCUSSION}

Factors influencing on the performance of MA-LPME including the kind and amount of ionic liquid, amount of chelating agent, $\mathrm{pH}$, microwave power, time of irradiation and ionic strength were evaluated in details and the 
optimized values were obtained.

\section{Kind of ionic liquid}

One of the major factors in the proposed microextraction is the kind of ionic liquid. The ionic liquid must show desire hydrophobic behavior, in order to the highest extraction efficiency take places. In addition, the density of ionic liquid must be high enough to collect at the bottom of the test tube after centrifugation. Some ionic liquid including 1-hexyl-3-methylimidazolium hexafluorophosphate, 1-butyl-3-methylimidazolium hexafluorophosphate, 1-butyl-3-methylimidazolium bromide were evaluated. The best performance and extraction recovery were obtained using -hexyl-3-methylimidazolium hexafluorophosphate. This ionic liquid was selected in all experiments.

\section{Effect of ionic liquid amount}

The impact of this parameter was studied in the range of $20-150 \mathrm{mg}$. As seen in Fig. 1, the sensitivity of the proposed protocol reaches to a maximum at $60 \mathrm{mg}$. In addition, the reproducibility of data in this value is acceptable. By increasing the amount of ionic liquid, the performance of the extraction improves. But after a certain value the enrichment factor of zinc decreases, which is due to the increase in the extracting phase volume. As a result a value of $60 \mathrm{mg}$ of ionic liquid was selected for further works.

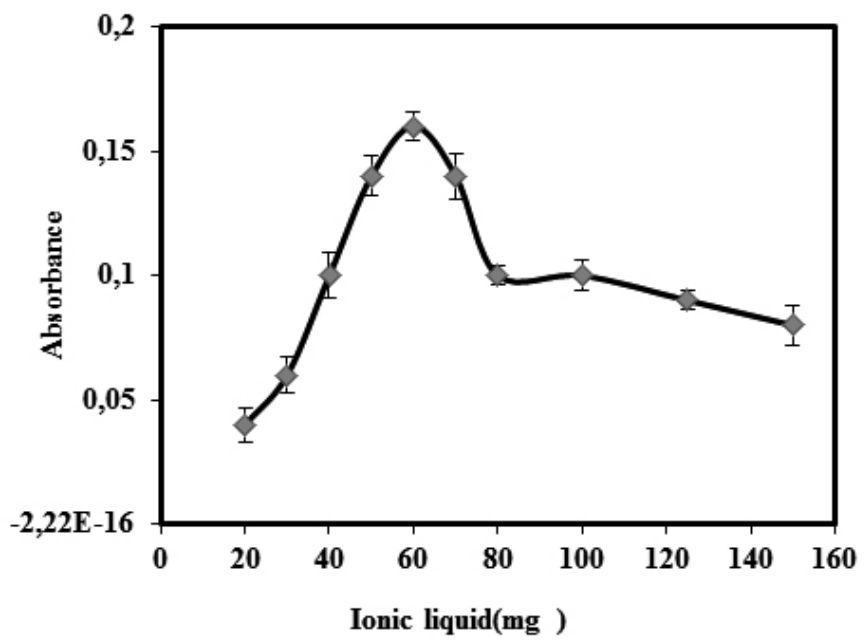
of zinc.

Fig. 1. Effect of ionic liquid amount on the extraction and determination

Effect of oxime amount (chelating agent)

Oxime shows proper selectivity toward heavy metals including $\mathrm{Zn}$, Al, etc and the rate of reaction between oxime and metallic elements is relatively high The influence of the amount of oxime as a chelating agent was investigated and the obtained results are illustrated in the Fig. 2. The concentration of oxime significantly, affect on the yield of the extraction. The concentration of oxime must be high enough, in order to ensure that complaxation of zinc has been completed. In order to obtain a compromise between yield of complexation, sensitivity of the signals and reproducibility, a concentration of $3 \times 10^{-5} \mathrm{~mol} \mathrm{~L}^{-1}$ of oxime was selected as the optimized amount.

\section{Effect of pH}

$\mathrm{pH}$ is a significant factor in the formation a complex of metals. The impact of this parameter was studied in the range of 5-11 using $\mathrm{HCl}$ and $\mathrm{NaOH}$ as the $\mathrm{pH}$ tuner. The obtained data are shown in Fig. 3. As it can be seen, the highest sensitivity can be obtained at $\mathrm{pH} 10$. So, this value was applied for all measurements.

Effect of microwave power and time of irradiation

The temperature caused by applying microwave, significantly increases the speed of mass transfer and extraction recovery. The generated heat has a main role on the extraction of zinc-oxime into the ionic liquid phase. Microwave irradiation dissolves the ionic liquid and disperses it completely through the aqueous sample. The effect of microwave power was investigated in the range of 100-500 W (Fig. 4). Acceptable sensitivity and reproducibility were obtained at $150 \mathrm{~W}$. So, this value of microwave power was selected for all experiments. The time of irradiation was investigated in the range of 30-100 s. The analytical signal increased as the time of irradiation increased. Maximum value was obtained at $75 \mathrm{~s}$. Microwave irradiation generates heat in the sample solution, as a result the solubility of ionic liquid increases and converts to tiny drops. Due to the complete dispersion of ionic liquid in the aqueous phase, the speed of extraction and analytical sensitivity improves.

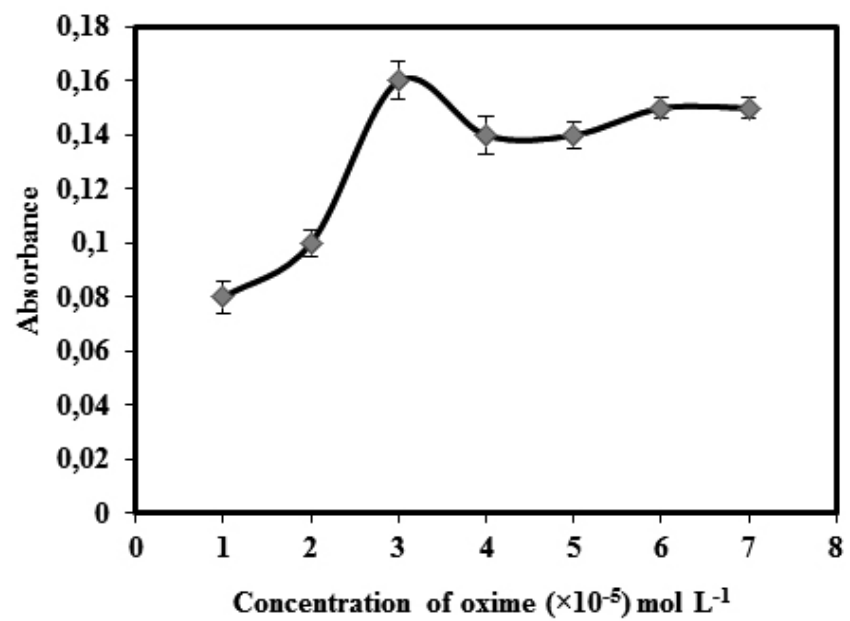

Fig. 2. Effect of oxime concentration on analytical signals.

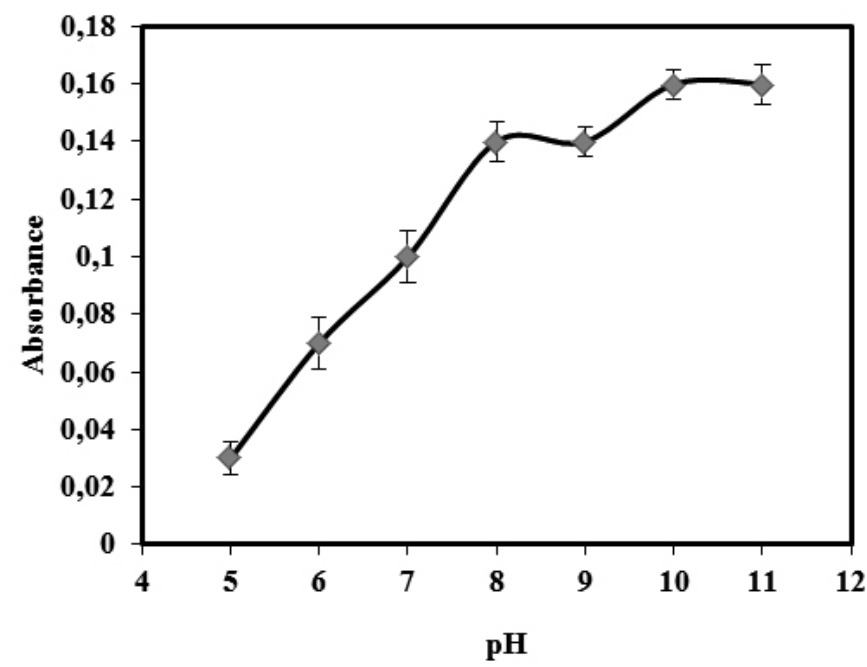

Fig. 3. Effect of pH on MA-LPME-FAAS.

Effect of ionic strength

Influence of salt concentration on the analytical signals and determination of zinc was evaluated by dissolving $\mathrm{NaCl}$ in the sample solution in the range of 0 to $15 \% \mathrm{w} / \mathrm{v}$. The results revealed that as the concentration of $\mathrm{NaCl}$ increased up to $5 \%$, the extraction of zinc-oxime and subsequently analytical signals increased. This fact is due a decrease in the solubility of zinc-oxime in an aqueous media. But after $5 \% \mathrm{w} / \mathrm{v}$ of $\mathrm{NaCl}$, the electrostatic interaction between salt and complex increased, which caused a low yield of extraction. As a result, $5 \% \mathrm{w} / \mathrm{v}$ of $\mathrm{NaCl}$ was used in all measurements. All the studied parameters and optimized values are shown in Table1. 


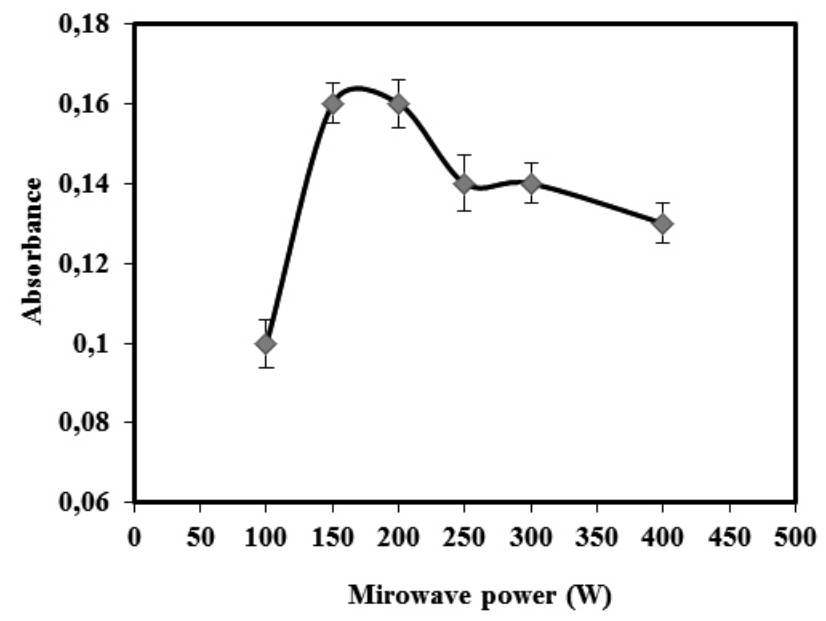

Fig. 4. Effect of microwave power on the extraction efficiency.

Table 1 : Evaluated factors and optimized values.

\begin{tabular}{|l|c|c|}
\hline Factor & $\begin{array}{c}\text { Investigated } \\
\text { range }\end{array}$ & $\begin{array}{c}\text { Optimum } \\
\text { value }\end{array}$ \\
\hline Amount of ionic liquid $(\mathrm{mg})$ & $20-150$ & 60 \\
\hline Amout of chelating agent $\left(\mathrm{mol} \mathrm{L}^{-1}\right)$ & $(1-7) \times 10^{-5}$ & $3 \times 10^{-5}$ \\
\hline $\mathrm{pH}$ & $5-11$ & 10 \\
\hline Microwave power $(\mathrm{W})$ & $100-500$ & 150 \\
\hline Time of irradiation $(\mathrm{s})$ & $30-100$ & 75 \\
\hline Ionic strength $(\mathrm{w} / \mathrm{v} \%)$ & $0-15$ & 5 \\
\hline
\end{tabular}

\section{Interference study}

In order to demonstrate the selectivity of the current method, some interfering ions as interfering agents were subjected to the analysis procedure. The effect of possible interfering agent on the analytical signals was investigated and the obtained results are summarized in Table 2. A change in signals more than $5 \%$ was defined as interference.

Table 2 : Interference study for trace determination of zinc.

\begin{tabular}{|l|c|}
\hline Ions & Interference-to-Zn(II) ratio \\
\hline $\mathrm{Co}^{2+}, \mathrm{SO}_{4}^{2-}, \mathrm{NO}_{3}^{-}, \mathrm{CH}_{3} \mathrm{COO}, \mathrm{F}^{-}, \mathrm{Cl}^{-}$ & 800 \\
\hline $\mathrm{Al}^{3+}, \mathrm{Cr}^{3+}$ & 600 \\
\hline $\mathrm{Pb}^{2+}, \mathrm{Ag}^{+}$ & 50 \\
\hline $\mathrm{Fe}^{3+}, \mathrm{Cu}^{2+}, \mathrm{Ni}^{2+}, \mathrm{Cd}^{2+}$ & 15 \\
\hline
\end{tabular}

\section{Application}

\section{Analytical figures of merits}

The proposed protocol provided a calibration range of 5-32 $\mathrm{ng} \mathrm{mL}^{-1}$. Four standards samples of zinc with a concentration of $15 \mathrm{ng} \mathrm{mL}^{-1}$ were analyzed in order to obtain relative standard deviation (RSD). The calculated value for RSD was $4.3 \%$. The limit of detection (LOD) was obtained by analyzing blank solution and dividing its standard deviation to slope of the equation of calibration curve. The obtained value was $1.5 \mathrm{ng} \mathrm{mL}^{-1}$ (see Table 3).

Table 3: Analytical parameters of MA-LPME-FAAS for quantification of zinc.

\begin{tabular}{|l|c|}
\hline Parameter & Analytical feature \\
\hline Calibration range $\left(\mathrm{ng} \mathrm{mL}^{-1}\right)$ & $5-32$ \\
\hline Limit of detection $\left(\mathrm{ng} \mathrm{mL}^{-1}\right)$ & 1.5 \\
\hline$(\mathrm{RSD} \%)(\mathrm{n}=4)$ & 4.3 \\
\hline Preconcentration factor $(\mathrm{PF})$ & 20 \\
\hline
\end{tabular}

Measurement of zinc in food samples

Different real food samples including potato, tomato, and wheat flour were analyzed with MA-LPME-FAAS. The obtained results are shown in Table 4.

The obtained recoveries are between 90.4-96.3\%, which demonstrates the applicability of the proposed method for the analysis of real sample. The proposed protocol is practical tool for trace analysis zinc in complex matrixes such as a food samples.

Table 4: Quantification of zinc in food sample by the presented method.

\begin{tabular}{|l|c|c|c|}
\hline Sample & $\begin{array}{c}\text { Added value }(\mu \mathrm{g} \\
\left.\mathrm{g}^{-1}\right)\end{array}$ & $\begin{array}{c}\text { Found value }(\mu \mathrm{g} \\
\left.\mathrm{g}^{-1}\right)^{\mathrm{a}}\end{array}$ & Recovery (\%) \\
\hline Wheat flour & - & $14.7 \pm 0.64$ & - \\
\hline & 15 & $26.30 \pm 1.20$ & 91.9 \\
\hline Potato & - & $11.29 \pm 0.56$ & - \\
\hline & 15 & $25.31 \pm 1.02$ & 96.3 \\
\hline Apple & - & $10.63 \pm 0.50$ & - \\
\hline & 15 & $23.17 \pm 1.13$ & 90.4 \\
\hline
\end{tabular}

${ }^{a}$ results are the average of three independent measurmets.

\section{CONCLUSION}

In this work, microwave-assisted liquid phase microextraction (MALPME) was followed by flame atomic absorption spectrometry for quantification of trace levels of zinc in food samples. 1-hexyl-3-methylimidazolium hexafluorophosphate $\left([\mathrm{Hmim}]\left[\mathrm{PF}_{6}\right]\right)$ ionic liquid (IL) is used as a green extraction solvent. In order to disperse the extraction phase into the sample solution and extract analyte of interest, microwave irradiation is utilized. There is no need for application a disperser solvent. The heat caused by applying microwave irradiation can dissolve and disperse the ionic liquid into the sample solution, which significantly improves the speed and efficiency of extraction The obtained results revealed that the proposed method is an efficient analytical method for trace analysis of zinc in food samples.

\section{ACKNOWLEDGMENT}

This work has been supported by grants from the Islamic Azad University - Tehran South Branch, which is hereby gratefully acknowledged.

\section{REFERENCES}

1. M. J. Khajeh, Hazard. Mater. 172, 385, (2009)

2. M. J.Salgueiro, M. B. Zubillaga, A. E. Lysionek,. R. A. Caro, R. Weill, J. R. Boccio, Nutrition 18, 510,(2002)

3. J. Borkowska-Burnecka, A. Szymczycha-Madeja, W. Zyrnicki, J. Hazard. Mater. 182, 477, (2010)

4. O. Acar, Aanl. Chim. Acta 526,103, (2004)

5. J. S. Carletto, K. C. D. P.Roux, H. F. Maltez, E. Martendal, E. Carasek, J. Hazard. Mater. 157, 88, (2008)

6. C. Terres-Martos, M. Navarro-Alarcn, F. Marin-Lagos, R. Giménez Martinez, De H. L. G. La Serrena, M. C. Lpez-Martinez, Water Res. 36, 1912, (2002)

7. J. A.Salonia, R. G. Wuilloud, J. A. Gsquez, R. A. Olsina, L. D. Martinez, Fresen. J. Anal. Chem. 367, 653, (2000)

8. S. Mahesar, S. Sherazi, A. Niaz, M. Bhanger, A. Rauf, Food Chem. Toxicol. 48, 2357, (2011)

9. S. S. Saei-Dehkordi, A. A. Fallah, Microchem. J. 98, 156, (2011)

10. M. Vega, M. Augusto, M. C. Talio, L. P. Fernindez, Am. J. Anal. Chem. 2, 902, (2011)

11. A. Niazi, S. Habibi, M. Ramezani, J. Chil. Chem. Soc. 58, 1899, (2013)

12. D. Afzali, M. Fayazi, A. Mostafavi, J. Chil. Chem. Soc. 58, 1593, (2013)

13. B. Mokhtari, N. Dalali, K. Pourabdollah, J. Chil. Chem. Soc. 57, 1428, (2012)

14. H. Yan, H. Wang, X. Qin, B. Liu, J. Du, J. Pharm. Biomed. Anal. 54, 53, (2011)

15. N. Hirayama, M. Deguchi, H. Kawasumi, T. Honjo, Talanta 65, 255, (2005)

16. M. Gharehbaghi, F. Shemirani, M. D. Farahani, J. Hazard. Mater. 165, 1049, (2009) 
17. S. Sun, Y. Wang, W. Z. Yu, T. Q. Zhao, S. Q. Gao, M. Q. Kang, Y. P. Zhang, H. Q. Zhang, Y. Yu, J. Sep. Sci. 34, 1730, (2011)

18. L. M. Ravelo-Pérez, J. Hernández-Borges, A. V.; Herrera-Herrera, M. A. Rodríguez- Delgado, Anal. Bioanal. Chem. 395, 2387, (2009)
19. L. Vidal, A. Chisvert, A. Canals, A. Salvador, Talanta 81, 549, (2010)

20. H. Abdolmohammad-Zadeh, G. H. Sadeghi, Talanta 81,778, (2010)

21. S. Wang, C. Liu, S. Yang, F. Liu, Food Anal. Methods 6, 481, (2013)

22. S. P. Wen, S. H. Zhu, Food Anal. Methods 7, 291, (2014) 